\title{
HUBUNGAN POLA ASUH ORANG TUA DENGAN PRESTASI BELAJAR MAHASISWA S1 KEPERAWATAN SEMESTER I STIKES BULELENG
}

\author{
(The Relationship between Parenting Parents and Student Achievement in First Grade of \\ Nursing Students in STIKes Buleleng)
}

\author{
Kadek Devy Marleni', Putu Windi Ridayanti ${ }^{2}$, Putu Agus Windu Yasa Bukian \\ Program Studi Ilmu Keperawatan Sekolah Tinggi Ilmu Kesehatan Buleleng \\ Email: devy26marleni@gmail.com
}

\begin{abstract}
ABSTRAK
Pendahuluan: Salah satu tujuan dari proses belajar mengajar adalah adanya perubahan tingkah laku baik aspek pengetahuan (kognitif), sikap (afektif), maupun aspek psikomotorik. Salah satu perubahan aspek kognitif siswa dapat dilihat dari indeks prestasi yang diperoleh. Indeks prestasi dijadikan sebagai tolak ukur penguasaan akademik siswa. Prestasi belajar yang dicapai siswa pada hakekatnya merupakan pencerminan dari usaha belajar. Dalam mencapai prestasi yang memuaskan selain harus belajar juga ditunjang dengan penerapan pola asuh yang tepat dari orang tua pada anak. Metode:jenis penelitian survey analitik dengan rancangan cross sectional, sampel dalam penelitian ini 54 responden dengan Teknik total sampling. Hasil:Hasil analisa data dengan uji Spearman's rho di dapatkan nilai $(0,000)$ atau $p<\alpha(0,05)$. Kesimpulan:Dari hasil penelitian tersebut dapat disimpulkan bahwa terdapat Hubungan Pola Asuh Orang Tua Dengan Prestasi Belajar Mahasiswa S1 Keperawatan Semester I

Kata Kunci: Pola Asuh Orang Tua, Prestasi, Mahsiswa
\end{abstract}

\section{ABSTRACT}

Introduction: One of the goals of teaching and learning process is a change in behavior in both of the knowledge (cognitive), attitude (affective), and psychomotor aspects. One change in the cognitive aspects of students can be seen from achievement index obtained. Performance index is used as a benchmark for students' academic mastery. Student achievement is essentially a reflection of learning effort. In achieving satisfaction achievements in addition to having to study it is also supported by the application of proper parenting from parents to children.Methods:analytic survey research type with cross sectional design, the sample in this study 54 respondents with the technique of total sampling. Result: The results of data analysis with the Spearman's rho test obtained a value (0,000) or $p<\alpha$ (0.05). Conclusions: From the results of this study it can be concluded that there is a Relationship between Parenting Parents With Learning Achievement of Students of nursing in first grade.

Keywords: Parenting, Student Achievement, Nursing Students

\section{PENDAHULUAN}

Salah satu tujuan dari proses belajar mengajar adalah adanya perubahan tingkah laku baik aspek pengetahuan (kognitif), sikap (afektif), maupun aspek psikomotorik (Sulasteri, 2016). Salah satu perubahan aspek kognitif siswa dapat dilihat dari indeks prestasi yang diperoleh.

Indeks prestasi dijadikan sebagai tolak ukur penguasaan akademik siswa. Semakin baik penguasaan akademik siswa, maka prestasi yang diperoleh pun akan baik pula. Prestasi belajar yang dicapai siswa pada hakekatnya merupakan pencerminan dari usaha belajar. Pada umumnya semakin baik usaha belajar maka semakin baik pula prestasi yang dicapai.
Proses belajar yang terjadi pada individu merupakan sesuatu yang penting, karena melalui belajar individu dapat mengenal lingkungannya dan menyesuaikan diri dengan lingkungan sekitar (Julia \& Ulfa, 2013).Penilaian terhadap hasil belajar seorang siswa untuk mengetahui sejauh mana telah mencapai sasaran belajar, inilah yang disebut sebagai prestasi belajar.

Berbagai laporan mengungkapkan bahwa prestasi belajar (academic achievement) peserta didik Indonesia kurang optimal. Kualitas pendidikan Indonesia seperti yang yang dilaporkan tersebut antara lain oleh The International Association for the Evaluation of Educational Achievement (IEA) Tahun 2011 
perlu dicermati dan ditindak lanjuti. (Yuzarion, 2012). Menurut Ayem \& Haryanto (2019) Faktor lain yang dapat mempengaruhi prestasi belajar siswa adalah perhatian orang tua.

Perhatian orang tua terhadap pendidikan putra-putrinya merupakan pemusatan energi yang di lakukan secara sengaja, intensif dan terkonsentrasi dari orang tua yang tertuju pada beberapa indikator berikut : (1) Bagaimana orang tua meyediakan kelengkapan sarana dan prasarana, (2) Bagaimana orang tua mengawasi pendidikan anaknya, (3) Bagaimana orang tua mengendalikan pergaulan anaknya yang dilandasi dengan rasa kasih sayang dan kesadaran yang mendalam, dalam usahanya untuk menunjang keberhasilan prestasi belajar putra-putrinya.

Dalam mencapai prestasi yang memuaskan selain harus belajar juga ditunjang dengan penerapan pola asuh yang tepat dari orang tua pada anak, karena apabila dalam menerapkan pola asuh salah maka akan berpengaruh buruk pada sikap dan pribadi anak sehingga akan mempengaruhi prestasi belajarnya. Sugiyanto (2015, dalam Manumbalang, Rompas, \& Bataha, 2017).

Pola asuh merupakan sikap dan perilaku orang tua dalam berinteraksi dengan anak, sikap dan perilaku orang tua tersebut dapat di lihat dari cara orang tua menanamkan disiplin pada anak, mempengaruhi emosi dan cara orang tua dalam mengontrol anak.

Berdasarkan studi pendahuluan dilakukan pada di STIKes Buleleng jumlah mahasiswa dan orang tua yang diwawancarai sebanyak 10 orang yang dipilih secara acak didapatkan hasil 8 siswa mengalami prestasi buruk dengan rata-rata nilai 65,5 dan 2 orang dengan rata-rata prestasi belajarnya 70 , itu disebabkan karena kurangnya kasih sayang, perhatian dan tertekan karena paksaan orang tua yang menginginkan anaknya untuk belajar, tetapi tidak ada niat belajar dari anaknya. Dari 10 siswa yang diwawancarai, didapatkan 5 orang tua dari mereka menggunakan pola asuh otoriter dengan alasan agar anaknya belajar dan tidak bermain game saja, 3 orang tua menggunakan pola asuh demokratis dan 2 menggunakan pola asuh permisif.

\section{METODE PENELITIAN}

Penelitian ini menggunakan jenis penelitian survey analitik dengan rancangan cross sectional. Jumlah sampel yang digunakan 54 mahsiswa. Penelitian ini akan dilaksanakan pada tanggal 17 - 22 Mei 2019, dan dilakukan selama 1 minggu Teknik sampling yang digunakanNon probability Sampling dengan teknik purposive sampling.

\section{HASIL PENELITIAN}

Tabel 1.1Distribusi Frekuensi Responden Berdasarkan Jenis Kelamin Mahasiswa S1 Keperawatan Semester I

\begin{tabular}{ccc}
\hline $\begin{array}{c}\text { Jenis } \\
\text { Kelamin }\end{array}$ & Frekuensi (f) & $\begin{array}{c}\text { Persentase } \\
(\mathbf{\%})\end{array}$ \\
\hline Laki-laki & 22 & 40,7 \\
Perempuan & 32 & 59,3 \\
\hline Total & $\mathbf{5 4}$ & $\mathbf{1 0 0}$ \\
\hline \multicolumn{3}{c}{ Sumber: Data Primer, 2019 }
\end{tabular}

Berdasarkan tabel 1.1 dapat dilihat bahwa dari 54 responden sebagian besar responden berjenis kelamin perempuan yaitu sebesar 32 responden $(59,3 \%)$.

Tabel1.2Distribusi Frekuensi Responden Berdasarkan Umur didi SMP N 4 Seririt.

\begin{tabular}{|c|c|c|c|c|c|c|}
\hline & $\mathbf{N}$ & $\begin{array}{c}\text { Mea } \\
\text { n }\end{array}$ & Min & $\begin{array}{c}\mathbf{M a} \\
\mathbf{k}\end{array}$ & SD & $\begin{array}{c}95 \\
\% \mathrm{C} \\
\mathrm{I}\end{array}$ \\
\hline Usia & 54 & 19,15 & 18 & 20 & $\begin{array}{c}0,73 \\
7\end{array}$ & $\begin{array}{c}18,9 \\
5- \\
20,3 \\
5\end{array}$ \\
\hline
\end{tabular}

Berdasarkan tabel 1.2 dapat dilihat bahwa rata-rata umur responden 19,15 tahun. Umur tertinggi responden 20 tahun dan umur responden terendah 18 tahun. Nilai Standar Deviasi dari karakteristik umur yaitu 0.737 , Confidence interval dari karakteristik umur responden antara 18,95 sampai 20,35 .

Tabel 1.3 Distribusi Frekuensi Responden Berdasarkan Pola Asuh Orang Tua pada Mahasiswa S1 Keperawatan Semester I

\begin{tabular}{ccc}
\hline Kategori & $\begin{array}{c}\text { Frekuensi } \\
(\mathbf{f})\end{array}$ & $\begin{array}{c}\text { Persentase } \\
(\mathbf{\%})\end{array}$ \\
\hline Sangat Buruk & 0 & 0,0 \\
Buruk & 12 & 22,2 \\
Cukup & 18 & 33,3 \\
Baik & 24 & 44,4 \\
\hline
\end{tabular}

http://ejournal.stikesbuleleng.ac.id/index.php/Midwinerslion | 71 


Total
Sumber: Data Primer, 2019
Berdasarkan Tabel 1.3 dapat dilihat
bahwa dari 54 responden di dapatkan hasil
sebagian besar responden berada pada kategori
baik sebanyak 24 responden $(44.4 \%)$.

Tabel 1.4 Distribusi Frekuensi Responden Berdasarkan Prestasi Belajar pada Mahasiswa S1 Keperawatan Semester I

\begin{tabular}{ccc}
\hline Kategori & $\begin{array}{c}\text { Frekuensi } \\
(\mathbf{f})\end{array}$ & $\begin{array}{c}\text { Persentase } \\
(\boldsymbol{\%})\end{array}$ \\
\hline Tinggi & 16 & 29,6 \\
Sedang & 29 & 53,7 \\
Rendah & 9 & 16,7 \\
\hline Total & 54 & 100 \\
\hline
\end{tabular}

Sumber: Data Primer, 2019

Berdasarkan tabel 1.4bahwa sebagian besar Prestasi Belajar berada dalam kategori sedang yaitu 29 orang $(53,7 \%)$.

Tabel 1.5Analisis Hubungan Pola Asuh Orang dengan Prestasi Mahasiswa S1 Keperawatan Semester I

\begin{tabular}{clc}
\hline \multicolumn{3}{c}{ Uji Korelasi Rank Spearman } \\
\hline & \multicolumn{2}{c}{ Prestasi Belajar } \\
\hline Pola Asuh & Correlation & $-0,666$ \\
Orang Tua & Coefficient & \\
\cline { 2 - 3 } & Sig & 0,000 \\
\cline { 2 - 3 } & $\mathrm{N}$ & 54 \\
\hline & \multicolumn{2}{c}{ Sumber: Data Primer, 2019}
\end{tabular}

Berdasarkan tabel 1.5 didapatkan hasil nilai $r=-0,666$ dan nilai $p$-value 0,000 dapat disimpulkan bahwa ada hubungan yang kuat, antara Pola Asuh Orang dengan Prestasi Mahasiswa S1 Keperawatan Semester I

\section{PEMBAHASAN}

Berdasarkan karakteristik responden diatas, dapat diketahui bahwa rata-rata usia Mahasiswa S1 Keperawatan Semester I yaitu 14,15 dengan usia termuda 13 tahun, dan tertua 15 tahun, dengan standar deviasi 0,737. Menurut peneliti salah faktor yang mempengaruhi prestasi belajar adalah usia karena usia remaja pada saat ini rentan mempengaruhi prestasi belajarnya karena seiring mengikuti lingkungan sekitarnya.

Berdasarkan jenis kelaminSebagian besar responden berjenis kelamin perempuan yaitu 32 orang $(59,3 \%)$. Menurut peneliti responden laki- laki maupun perempuan akan cenderung sama dalam prestasi belajarnya karena itu semua tergantung dari individu masing-masing dan pola asuh asuh orang tua.

Berdasarkan Pola asuh orang Tua menunjukkan bahwa mayoritas Pola Asuh Orang Tua berada dalam kategori baik 24 orang (44,4\%), cukup 18 orang $(33,3 \%)$, buruk 12 orang $(22,2 \%)$, sangat buruk $0(0,0 \%)$. Menurut asumsi peneliti pola asuh yang baik dan benar serta tanpa adanya tekanan akan membuat anak tersebut merasakan kasih sayang dan perhatian sehingga dapat memperbaiki cara mereka untuk belajar dan meningkatkan prestasi di sekolah.

Berdasarkan prestasi belajar menunjukkan bahwa mayoritas Prestasi Belajar berada dalam kategori sedang 29 orang $(53,7 \%)$. Menurut asumsi peneliti prestasi belajar yang sedang dipengaruhi oleh faktor dari orang tua yang kurang memperhatikan dan kurang motivasi dari orang tua mereka sehingga mengakibatkan siswa kurang semangat dalam belajarnya.

Hasil penelitian yang dilakukan di dapatkan hasil tabulasi orang tua yang memiliki pola asuh buruk dengan prestasi belajar siswa sedang 3 orang $(5,6 \%)$ rendah 9 orang $(16,7 \%)$, orang tua yang memiliki pola asuh cukup dengan prestasi belajar siswa sedang 18 orang $(33,3 \%)$, sedangkan orang tua dengan pola asuh baik dengan prestasi belajar siswa tinggi 16 orang $(29,6 \%)$ sedang 8 orang $(14,8 \%)$.

Berdasarkan uji statistik Spearman Rank menunjukan nilai $r=-0,666$ dan nilai $p$-value 0,000 dapat disimpulkan bahwa ada hubungan yang kuat, antara Pola Asuh Orang dengan Prestasi Belajar Mahasiswa S1 Keperawatan Semester I. Dari hasil uji statistik menunjukan Ho ditolak dan Ha diterima sehingga antara Pola Asuh Orang dengan Prestasi Mahasiswa S1 Keperawatan Semester I memiliki hubungan yang signifikan dan memiliki arah hubungan yang negatif.Menurut teori Suharsimi Arikunto (2010, dalam Donata, 2015) mengungkapkan bahwa kegiatan evaluasi yang dilaksanakan bertujuan untuk mengetahui berhasil atau tidaknya proses pembelajaran yang telah dilakukan dengan melihat dari prestasi belajar siswa, dan pola asuh yang diterapkan oleh orang tua pada anak sangat berpengaruh pada kepribadian yang dimiliki anak, dan kepribadian itu akan mempengaruhi prestasi belajar yang dicapai anak.

\section{SIMPULAN\&SARAN}

http://ejournal.stikesbuleleng.ac.id/index.php/Midwinerslion | 72 


\section{SIMPULAN}

Hasil uji statistik Spearman Rank, di dapat nilai $P<0,05 \mathrm{Hal}$ ini menunjukkan terdapat ada hubungan yang kuat, antara Pola Asuh Orang dengan Prestasi Belajar Mahasiswa S1 Keperawatan Semester I. Dari hasil uji statistik menunjukan Ho ditolak dan Ha diterima sehingga antara Pola Asuh Orang dengan Prestasi Mahasiswa S1 Keperawatan Semester I memiliki hubungan yang signifikan dan memiliki arah hubungan yang negatif.

\section{SARAN}

Hasil penelitian ini dapat dijadikan sebagai informasi dan data tambahan dalam penelitian keperawatan untuk pengembangan penelitian selanjutnya dalam ruang lingkup yang sama dan bisa menjabarkan faktor-faktor yang mempengaruhi prestasi belajar selain yang dijelaskan oleh peneliti.

\section{DAFTAR PUSTAKA}

Donata, E. (2015). Pengaruh Kebiasaan Belajar Dan Perhatian Orang Tua Terhadap Prestasi Belajar Akuntansi Siswa Kelas Xii Ips Sma Negeri 1 Pleret Tahun Ajaran 2014/2015 Skripsi.

Julia, P., \& Ulfa, A. (2013). Hubungan Antara Pola Asuh Orang Tua Dengan Hasil Belajar Siswa Pada Kelasiv Sd Negeri 10 Banda Aceh.

Manumbalang, S. T., Rompas, S., \& Bataha, Y. B. (2017). Hubungan Pola Asuh Dengan Status Gizi Pada Anak Di Taman Kanak-Kanak Kecamatan Pulutan. EJurnal Keperawatan, 5(2), 1-8. Https://Doi.Org/10.1166/Jnn.2017.15040.

Sulasteri, S. (2016). Faktor-Faktor Yang Mempengaruhi Prestasi Belajar Mahasiswa Jurusan Pendidikan Matematika Fakultas Tarbiyah Dan Keguruan Uin Alauddin Makassar, 151177.

Yuzarion. (2012). Faktor Yang Mempengaruhi Prestasi Belajar Peserta Didik, (1996). 